\title{
Mediating planning disputes: Opportunities, experiences and challenges
}

\author{
Andrew Agapiou \\ Senior Lecturer, Department of Architecture, University of Strathclyde, James \\ Weir Building, 75 Montrose Street, Glasgow, G1 1XJ, Scotland, UK.
}

\begin{abstract}
There is no dearth of academic research into the apparent benefits of mediation as a tool for the resolution of planning disputes. Several eminent lawyers have proffered their support for the use of this alternative dispute resolution mechanism within the UK planning system. Further, formalised mediation regimes have been introduced into the respective planning systems of a number of international jurisdictions, with apparent success; for example, in Australia, 34\% of all planning disputes are now resolved via a form of mediation. Notwithstanding this apparent evidence-base, in England and Wales a substantial number of property developers, local authorities and planning professionals continue to believe that mediation is not useful or appropriate as a mechanism for resolving planning disputes and, despite early indications that a formalised mediation regime would be developed and adopted in England and Wales, to date no such regime has been implemented. This present research paper seeks to examine through black letter analysis and semi-structured interview why this apparent 'mediation paradox' continues to exist and critically evaluates whether or not there does indeed exist a 'business case' for the introduction of a formal mediation regime within the UK planning system.
\end{abstract}

\section{Introduction}

Globally, mediation has proven to be extremely successful in enabling disputing parties to engage in a constructive rather than destructive manner (Golberg, 2003). For example, in the context of construction disputes, which typically involve complex agreements and time-sensitive contracts, mediation enables a particular dispute to be solved quickly so that the contract itself does not become frustrated. This is just one reason why construction and commercial contracts often feature a mediation/arbitration clause, so as to avoid lengthy and costly litigation. It moreover provides for a cost-effective and swift method of solving disputes in a more informal manner than litigation. Such benefits produce the expectation that mediation of planning disputes will result in quicker decisions, reduced time in determining applications, greater efficiency and an overall cheaper system. However, it is important to recognise that mediation is not automatically more beneficial than litigation, and its role and advantages depends on the type of dispute involved. It is also important to point out that mediation depends ultimately on the consent of the parties, and hence to impose it as a compulsory method of dispute resolution would undermine the very qualities and advantages that it claims to have over litigation. The purpose of this paper is therefore to consider mediation in the context of planning disputes in the UK, with a view to determining its potential role, opportunities and challenges. This will be applied to determine the viability of mediation for planning disputes in the UK, and whether a framework can be developed and structured to ensure that maximum benefit is gained from using mediation for such disputes. 


\section{Research Context}

As has been briefly addressed above, mediation provides a more cost-effective, faster and generally more beneficial form of dispute resolution than litigation for certain types of disputes. It is for these reasons that mediation may be considered a potentially useful form of dispute resolution in the field of planning disputes in the UK. Mediation for such disputes promises to facilitate participation in planning disputes on a much broader level, thereby promoting inclusiveness, and allowing for a broader and thus more accurate range of interests to be taken into account. The flexible nature of mediation also enables the process to be tailored according to the particular features of the individual case (Bacow and Wheeler, 2013). It is within this context that the potential benefits of mediation planning disputes should be approached and considered, in order to determine whether such benefits are applicable to this type of dispute.

The potential for mediation in the field of planning disputes has certainly not gone unnoticed in the UK. In 1996, a public debate was commenced by Chief Planning Inspector Chris Shepley concerning the potential benefits that mediation could offer and planning disputes (Shepley, 2013). It also addresses certain important features and qualities of mediation that would need to be maintained and protected in order for the benefits of mediation to become realised. This is an important issue, because it addresses the fact that the success or failure of mediation for planning disputes depends largely on how the mediation process is structured for such disputes. Shepley for example emphasises the need to maintain certain core standards in mediation for planning disputes, such as its voluntariness and confidentiality. He also stresses that mediation should "not affect the rights of applicants to go on to appeal, in the normal way; or the rights of local authorities to make democratic decisions".(Shepley, 2013; pg 49) Academic attention has also been given to such issues, with prominent focus on the successes of mediation for planning disputes in other jurisdictions, such as the US (Stubbs, 1997). Such interest did not however provoke any major reforms in the UK; it merely resulted in the publication of policy guidance and recognition of the potential benefits of mediation for such disputes (DCLG, 2006). Given the recognised advantages of mediation in the field of planning disputes, it is quite surprising that no major practical changes have been implemented in the UK. This forms the main context of the research, in that it recognises and acts upon the need to progress from theory to practice, and to develop an effective mediation framework for planning disputes. It is moreover important to draw experience from other jurisdictions in which mediation is used for such disputes.

The most prominent is Scotland, although other jurisdictions such as Australia and the US will also prove helpful. Identification of the advantages and challenges of such a system will provide useful guidance on whether, and if so, how, a mediation framework for planning disputes could be structured and implemented in the UK. It is difficult to doubt or undermine the benefits that mediation has the potential to offer planning disputes. It has for example been recognised that it could reduce appeals, in that problems could be eased at an early stage rather than resorting to an expensive and time-consuming appeal process (Barker, 2007). 
The UK government has however taken relatively few tentative steps towards promoting mediation for planning disputes. It has, for example, merely expressed that it "support[s] the voluntary use of mediation within the planning system", and recognised the need to "work with relevant professional bodies to promote mediation services by local authorities"(HM Government, 2007). It appears that policies and plans have lost pace when they reach the implementation stage, giving rise to the need to determine how a mediation framework for planning disputes may be best implemented, and what such a framework would need to contain. Planning disputes do not typically involve disputes concerning rights; they rather feature a disagreement between a local authority and a landowner about what they consider to be appropriate (Watson, 2016). This becomes all the more complicated due to the fact that third parties are able to participate in and contribute to the debate. Planning disputes may therefore often be more accurately defined as debates. This further supports the claim that mediation is better suited to such disputes/debates because it provides an arena for voicing opinions and arriving at a negotiated outcome (Kaufmann et al, 2014). It is therefore clear that there is convincing evidence to suggest that mediation may play an important and valuable role in solving planning disputes. It is further necessary to ensure that the mediation process is tailored to suit the particular features of land disputes, so that potential problems and challenges may be avoided or minimised. Examples from other countries in which a structured mediation regime for planning disputes has been implemented will provide guidance in this respect.

This research is of considerable importance for a number of reasons. First, if mediation is indeed a cost-effective tool for the expedient resolution of planning disputes, then the adoption of a formalised mediation regime the UK could accelerate investment into the respective property sectors of England and Wales. After all planning disputes delay developments and, consequently, a dispute resolution mechanism which can facilitate an earlier settlement of such disputes will ensure a faster realization of the benefits of development projects, including but not limited to higher levels of taxation revenue, employment, and housing stock (IRS, 1971). A study commissioned by the UK Government in 2002 estimated that the adoption of a formal mediation regime within the UK's planning sector would result in the realization of $£ 3$ billion of investment into the UK economy 40 weeks earlier than would be the case if all planning disputes were resolved via formal litigation. The findings of this study suggest that there is indeed a strong evidence-base in support of the adoption of a formal mediation regime within the UK's planning system.

Second, planning appeals in the UK cost the Exchequer around $£ 25$ million each year (Planning Inspectorate, 2010), and substantially more still for the developers and local authorities embroiled in these formal proceedings (Ratcliffe et al, 2009). If mediation is a cost-effective and viable alternative to formal litigation, then its widespread adoption would almost certainly result in a reduction in the number of appeals being lodged each year and a substantial cost saving for all parties involved and the Exchequer (Ratcliffe et al, 2009).

Third, there is evidence that the UK government is seeking to promote the development of a less centralised and more community-oriented planning system (Pemberton et al, 2015); for example, the Planning and Compulsory Purchase Act 2004 and the Planning Act 2008, both emphasise-and give a statutory footing tothe importance of efficient pre-application procedures and community participation. While mediation is only required after a dispute has arisen, as opposed to at the pre- 
application stage, nevertheless there is a clear synergy between the objectives of mediation and this emerging public policy agenda. Ultimately, the overriding objectives of this agenda are to increase stakeholder participation and to reduce the number of formal planning appeals being lodged with the courts. If mediation can help the parties to resolve their disputes without recourse to the formal appeals process, then at least the latter of these two agenda will be promoted, albeit at the post-application stage. Whether or not mediation is simultaneously capable of enhancing stakeholder participation is something that will be discussed at length within the body of this paper. Traditionally, mediation was developed as an informal and private mechanism for the confidential resolution of bilateral or bipartisan disputes; however, it will be argued in this paper that mediation is a highly flexible process and this form of Alternative Dispute Resolution (ADR) has no intrinsic qualities or characteristics that would preclude it from being modified to accommodate a wider number of community participants. So long as the expectations of the parties are managed appropriately, and a suitable form of mediation is adopted, this ADR mechanism can be an excellent way of allowing a wider range of stakeholders to participate in the negotiation process than would ordinarily be entitled to participate in the judicial appeal process (MacLaren et al 2007).

\section{Research Issues, Aims and Objectives}

The first research issue relates to the potential benefits that mediation provides in planning disputes, both in its own right, and in comparison to litigation. This will provide a basis for developing specific conclusions and reasoned arguments pertaining to the benefits of mediation for planning disputes. This then gives rise to the research issue pertaining to the potential disadvantages of mediation for planning disputes. This is an important issue, because it recognises that mediation is not automatically advantageous for all mediation disputes. The objective of this research area is to balance the potential advantages and disadvantages of mediation for planning disputes. This will provide a formula for determining how a mediation framework may best emphasise the advantages and eliminate the disadvantages of mediation for planning disputes, by reference to, for example, mediator training and confidentiality. Example in this context will be drawn from planning mediation regimes in other countries, in order to determine their strengths and weaknesses, and how a similar, improved framework may be established and implemented in the UK. Other jurisdictions in which mediation is used to resolve planning disputes will be examined, in order to determine how they are applied, and their failures and successes.

The research paper seeks to (i) evaluate the viability of mediation as a mechanism for the resolution of planning disputes which occur between developers and public authorities, (ii) identify the barriers to the uptake of mediation within the planning system of England and Wales; and, (iii) derive recommendations for legal and political reform to bring England's planning system in line with some of its more progressive counter-parts, such as Australia and Scotland.

\section{Research questions}

These aforementioned research issues, aims and objectives may be outlined as encompassing the following research questions: 
(i) Is mediation more cost-effective than formal litigation and ADR in resolving planning disputes? How can this cost-effectiveness be measured? What is the 'mediation paradox' and is it a paradox, after all?

(ii) What issues routinely characterise planning disputes and how might mediation better be suited to the resolution of these kinds of dispute over formal litigation and other forms of ADR?

(iii) Is mediation an appropriate mechanism for the resolution of disputes between private developers and public authorities?

(iv) What lessons may be learned from the respective mediation regimes for planning disputes in Scotland and Australia and how might these regimes inform planning law and policy in England and Wales?

(v) Is there a compelling business case for the introduction of a formal mediation regime within the UKs planning sector? In any event, what recommendations for reform can be proffered as a result of this findings of this present study?

\section{Methodology}

The primary methodology of this research takes the form of black-letter analysis.

For each research question identified above, a set of core database search terms were derived, which were used to locate relevant textbooks, sections in edited textbooks, journal articles, case reports, legislation, government consultation papers and newspaper articles. Relevant facts, figures and arguments were then extracted from these sources and categorised broadly into (i) data highlighting actual (empirical) or potential (theoretical / academic) benefits of mediation in planning; (ii) data revealing actual or potential challenges and barriers to the adoption of mediation in planning; and, (iii) data providing insights into the legal and political reforms required to exploit those advantages and/or overcome those barriers.

In addition, a semi-structured interview was conducted with a Planning Director at the London branch of Nathanial Litchfield and Partners, the UK's pre-eminent planning and development consultancy. The purpose of this interview was to glean an expert practitioner's perspective on the various barriers to the increased uptake of mediation by developers and local authorities in England and Wales. It was hoped that this primary research would reveal certain cultural or practical barriers to the uptake of mediation in this context which are not so readily identifiable from black-letter analysis of the academic literature alone. In addition, because developers usually act on the advice of their planning consultants, the interviewee's own opinion on the merits or otherwise of mediation within planning is directly relevant.

The semi-structured interview methodology was selected to ensure that the interview process was sufficiently flexible to allow this researcher to explore any novel issues which were raised by the interviewee during the interview (Crichton et al, 2013). This was particularly helpful as the interviewee raised a number of interesting issues and perspectives which this present author had not identified from the black-letter analysis undertaken during the preliminary stages of this research project.

While the reliability of the data obtained from this interview is tempered by the fact that the sample population comprised only one individual, this was more than mitigated by 
the expertise and seniority of the interviewee, whose team is directly responsible for the strategic management of a property portfolio valued in excess of $£ 1$ billion. If a Planning Director at Nathaniel Litchfield and Partners holds a particular viewpoint on the merits of mediation, that viewpoint is highly likely to be representative of the professional opinions of a substantial number of consultants and professionals within her industry. An "expert interview" with a small number of senior professionals is preferable, in terms of data quality, than a greater number of semi-structured interviews with persons with less relevant professional expertise (IAC-MEBM, 2016).

The results from the semi-structured interview will not be analysed individually; instead, this author will cite relevant excerpts from the transcript of the interview to support arguments made throughout this paper.

\section{Definitional and methodological uncertainty; defining and evaluating the cost- effectiveness of mediation, as opposed to formal litigation or other forms of ADR.}

In this section, this author examines the difficulties in defining a working definition for the term 'mediation' and explains the implications of this definitional and conceptual uncertainty for reliable international comparative analysis and also for evaluating the cost-effectiveness of mediation, as compared to formal litigation or, indeed to other forms of ADR. It is concluded that the primary rationale for this present study is not as convincing as it appeared during the preliminary research phase of this project.

The problem of deriving a working definition for the term 'mediation'

It is no straightforward task to derive a working definition for the term mediation (Morassso, 2011). The term and the process of mediation are used in so many different contexts (Nicholson, 2009) —legal and non-legal—that it is difficult to derive one singular definition which encompasses all essential characteristics of this process (Barsky, 2009). Definitions which do attempt to achieve generality are invariably too simplistic to be useful to an academic researcher. For example, Schrumpf et al define mediation as, " $\ldots$ a communication process in which the people with the problem work together, with the assistance of a neutral third party, cooperating to resolve their conflict peaceably (Schrumpf et al, 1997)" This definition provides no real insight into the nature of the mediation process, the role of the mediator-beyond the fact that mediators are 'neutral'-or the nature of the outcome of the process. It is also not entirely clear that this definition is capable of distinguishing mediation from other types of ADR, such as conciliation [1]

Those definitions which are sufficiently specific to serve as a working definition for the term mediation, tend to be limited to a specific context or to a particular variant of mediation or to one or more author's personal conceptions of the process or a variant 
thereof, and are therefore also of limited use. For example, even though it is generally agreed that there exist five main types of mediation-facilitative, evaluative, transformative, therapeutic and narrative mediation (Brooker,2013) - there is no general consensus as to the meaning of these terms and different authors tend to adopt their own prescriptive or descriptive definitions for this nomenclature. Bush and Folger, for example, define 'transformative mediation' through reference to a process of human development which involves a transformation in the behaviour of the actors involved in the mediation process (Spencer and Brogan, 2007); whereas, Boulle and Nesic have an entirely different conception of 'transformative mediation', and use the terms 'transformative mediation' and 'therapeutic mediation' interchangeably (Brooker, 2013: pg 8).

In the introduction to this paper, this author stated that there is wide support in the academic literature for the adoption of a formal mediation regime within the UK's planning system. One would have thought, by now-bearing in mind that this debate originates from the mid-1990s - that a single working definition for the term 'mediation' or at least for the preferred type of types of mediation would have emerged from the planning literature. Unhelpfully, this is not the case; in fact, it is not uncommon for academic articles dedicated to the promotion of this agenda to avoid altogether any attempt to define this term or to specify which type of mediation they are advocating. This could help to explain why, to date, this recurrent agenda has failed to be implemented in the UK; if there is no broad agreement on the form that the mediation process comprising this formal regime should take then how can the authorities be expected to know which type of mediation process and (accompanying) procedure to prescribe?

The lack of definitional certainty in this area is perhaps itself a result of the informal nature of mediation and the wide degree of autonomy which is given to mediators to decide how to bring the disputing parties towards consensus (Brooker, 2013; pg 1). As Chern argues, "There are as many different types of mediation as there are mediators (Chern, 2014)." In the UK, the focus of mediation training is on the 'facilitative' and 'evaluative' varieties (Chern, 2013); however, in practice, the professional experience and instinct of the mediator is more likely to guide the mediation process than his or her formal training. This view is supported empirically; various studies have found that one of the more reliable predictors of the success of mediation is the skill and experience of the mediator (Roberts, 2014). In practice, this means that there must be a high level of inconsistency in the success rates between different mediators (Bercovitch and Jackson, 2009). This inconsistency may help to explain why there seems to be such wide disparity between the success rates of mediation within different nation states. For example, in Canada and New Zealand, the success rates of mandatory mediation are $80 \%$ and $73 \%$ respectively; whereas, in England and France, the published success rate for mandatory mediation is $50 \%$ or lower (Hopt and Steffek, 2013). A wide variety of different forms of mediation are being practiced internationally, within entirely different legal and cultural environments, by mediators with different types and level of training and experience, and consequently there is a wide disparity between the success rates of mediation within different nation states. 
The implications of this uncertainty for this present study and the difficulty in and other forms of ADR: Debunking the 'mediation paradox'.

The implications of this uncertainty and inconsistency for this present study are potentially profound. In order to build a 'business case' for the adoption of a formal mediation regime in the UK's planning system, it is necessary to present compelling evidence that mediation is likely to be more cost-effective at resolving planning disputes than either formal litigation or other forms of ADR. Intuitively, it seems that the best source from which to derive this evidence is empirical data from other jurisdictions which have already adopted such a regime, successfully. However, in practice, due to the disparity identified supra, it is now clear that this methodology is flawed; simply stated, there are too many different factors which affect the success rate of mediation to defend the assertion that a particular mediation regime would be effective in the UK, on the basis that it has proven to be effective in another jurisdiction.

This does not mean that lessons cannot be learned from other jurisdictions which have implemented a formal mediation regime successfully; however, it does mean that recommendations for reform cannot be based solely upon international experience. It also means that one has to be very careful to examine the processes and procedures which are being employed by these successful regimes, avoiding wherever possible the use of popular nomenclature, such as 'mediation' and 'facilitative mediation', which denotes a degree of generality which, simply stated, does not exist. As Poon writes, "...there are so many different styles and approaches [to mediation] that labels cannot capture them accurately (Poon, 2010)." Failure to heed this warning could result in the well-intentioned, but totally meaningless, comparison of 'apples' and 'oranges' or, worse, a proposal to adopt 'apples' to do the job of 'oranges', because 'fruit' has proven to be effective in a foreign jurisdiction. Ardent proponents of mediation attempt to overcome these challenges by asserting that mediation is more cost-effective than litigation, even if the success rate of mediation is inconsistent. Mediation is so inexpensive as compared to formal litigation, they argue, that even if success rates are low, the additional expenses incurred as a result of failed mediation are insignificant compared to the cost-savings which result from a successful mediation and the avoidance of court litigation (MacNaughton and Martin, 2002).

To these commentators, the lack of uptake of voluntary mediation therefore represents a 'paradox' of sorts; these authors cannot comprehend why a rational actor would not choose to participate in mediation when its cost-benefits are so obvious (Cortez, 2016). To these authors, the lack of uptake of this form of ADR can therefore only be explained through reference to factors other than cost-effectiveness.

In the opinion of this present author, and for reasons which will be explained below, the 'mediation paradox' is not a paradox at all. In fact, there are legitimate and rational reasons for disputants to choose to forego voluntary mediation and proceed directly to formal litigation.

For one thing, the cost-effectiveness argument fails to take into account the other 'costs' of a failed mediation, such as the delay in resolving the dispute (Agapiou and 
Ilter, 2016) and the fact that the parties to a failed mediation may have inadvertently compromised their legal positions by revealing their respective legal strategies to their opponents during the mediation process (Clark, 2007). It also fails to take into account the fact that disputes which are resolved by mediation may have been resolved in any event, through negotiation, prior to trial (Clark, 2012). Further, the parties to a mediation may decide to appoint legal professionals to represent their interests, and consequently, mediation may prove to be just as costly as formal litigation, especially since these extra-judicial legal costs cannot usually be recovered in most jurisdictions (Susskind et al, 2000). Furthermore, the cost-effectiveness of mediation needs to be evaluated within the context of the specific legal system in which it is taking place; legal rules governing mediation can affect substantially the relative cost-effectiveness of this process (Alexander, 2008).

In any event, there is no reliable empirical methodology available to test the veracity of this pro-mediation argument. Not only would the findings of such a study lack external validity due to the inconsistencies discussed previously in this section, unless the sampling was sufficiently broad and data extracted from a sufficiently wide crosssection of different types of 'mediation' from the same jurisdiction, but hypothetical assumptions would also need to be made about the likely costs of resolving by court litigation disputes which have been resolved successfully through mediation. This would be required in order to prove that the cost-savings enjoyed by the parties to successful mediations exceed the additional costs expended by the parties whose mediations were not successful. Unsurprisingly, the few noteworthy attempts that have been made to empirically test the cost-effectiveness of mediation (as comparted to litigation) (Bondy and Mulcahy, 2009) have been as inconsistent as the definition of 'mediation' and the published success rates of this form of ADR.

As Brian Clark writes, "While hyperbolic, anecdotal claims as to the cheapness of mediation abound, the empirical evidence on the issue of cost-effectiveness is more mixed. Discernable cost benefits for parties may vary wildly of course depending on context (Clark, 2012)" In fact, there is a body of empirical evidence supporting the view that mediation may not be a cost-effective dispute resolution mechanism at all, especially if the mediation process is court-connected or mandatory (Agapiou and Ilter, 2016). While these studies are also methodologically flawed, they nevertheless demonstrate conclusively that the cost-effectiveness of mediation cannot be taken at face-value, however intuitive the arguments of its proponents may appear to be.

\section{Revisiting the rationale for this present study and the conclusions of this section.}

In the introduction of this paper, this author cited the findings of a study commissioned by the UK Government in 2002 which estimated that the adoption of a formal mediation regime within the UK's planning sector would result in the realization of $£ 3$ billion of investment into the UK economy 40 weeks earlier than would be the case if all planning disputes were resolved via formal litigation.

In light of the preceding analysis it seems quite clear that the findings of this government-funded study must be treated with a high level of scepticism; bearing in mind the uncertainties and inconsistencies identified in this section, especially those 
pertaining to the challenges of relying upon international comparative analysis in this context, there is simply no methodology available which could produce reliable results with this level of quantitative specificity.

The focus of the preceding analysis was limited to a comparison between the costeffectiveness of mediation and court litigation. However, logically, the same conclusions and concerns derived above are equally applicable to a comparison between the cost-effectiveness of mediation and other forms of ADR.

In conclusion, it must be argued that presently there does not exist an adequate evidence-base from which to justify the implementation of a formalised mediation regime within the UK's planning system, on grounds of cost-effectiveness alone. Consequently, in order to justify the introduction of such a regime, it is necessary to take a step backwards, and look specifically at the nature of planning disputes to see if there exist other measurable barriers to efficiency, in this context, which might be overcome, measurably, through the adoption of a formalised mediation regime. For example: In the introduction to this paper it was argued that the UK government is committed to improving community participation in the planning system; if mediation could improve stakeholder participation in an appropriate way, then this could be a legitimate ground in its own right for introducing a formal mediation system within the UK planning system. 

present paper, the term is used narrowly to refer to those disputes which arise between developers and local authorities, prior to, during or after the grant of 'planning permission', i.e. permission to develop or commercialise real estate in a certain way.

Because of the intrinsic value of real estate, the outcome of a planning dispute can have substantial economic impacts on the parties. A successful application for planning permission can add considerable value to a developer's land. Conversely, an unsuccessful application can reduce considerably the value of that land, by confirming that the land in question does not enjoy short- or medium- term development prospects. A successful planning application can also have profound positive and/or negative impacts upon the community at large, depending upon the nature of the proposed development and its likely impact on the aesthetics, economy, infrastructure and citizenship of the affected locality. Therefore, planning disputes are rarely frivolous or vexatious, and they are invariably contentious, as they navigate those difficult waters which exist at the interface of private rights and public interests (Levy, 2016):

Private developers understandably wish to maximise the land value of their real estate holdings, and are therefore likely to pursue aggressive and ambitious development strategies (Barlow and Duncan, 2004). Local authorities welcome planning applications for such schemes, as privately-funded property development can bring considerable benefits to the local area, including new housing stock, infrastructure, local amenities and aesthetic enhancement. However, all large-scale developments will have both positive and negative impacts upon the local community, and local authorities must consider each planning application carefully on its own merits, to ensure that the overall impact of any approved scheme is likely to be positive (Crook et al, 2016). This utilitarian approach to planning decision-making enjoys a statutory footing. For example, section 106 of the Town and Country Planning Act 1990 (as amended) adopts a mechanism through which developers may offer local authorities incentives to offset the potential negative impacts of their proposed development schemes (Jansen et al, 2008), for example, by providing a sum of money for local authorities to invest in public amenities (Cullingworth et al, 2014).

Planning disputes may arise for a number of different reasons. However, in practice, the vast majority of planning disputes arise where a developer believes that a local authority has failed to discharge its duties or powers properly or in a timely manner and commences formal litigation against the local authority to appeal that decision or compel a determination (Isaac et al, 2016). The substance of such a dispute usually hinges around the correct interpretation and contextual application of a particular law or policy. As Pauline Roberts, of Nathaniel Litchfield and Partners, explains, "It all comes down to planning law and compliance with the statutory development plan. Proposals either comply with the statutory development plan or they don't. Recourse is the appeal procedure or judicial review if an unlawful process has taken place." 
Consequently, planning disputes are atypical-as compared to traditional claimantdefendant litigation-because they arise when developers and planners have different views of what is appropriate, rather than as a result of the alleged infringement of a right, per se. This viewpoint is supported by Sir Henry Brooke who explains the nature of planning disputes, succinctly:

\begin{abstract}
A typical planning dispute does not involve a dispute between parties about a right. It is an argument between a landowner and a local authority about what is appropriate... It is wrong to assume that an applicant for planning permission, or an appellant who challenges a refusal of planning permission, can be equated with a claimant in civil litigation, with the local authority in the role of a defendant [Brooke, 2015].
\end{abstract}

These kinds of dispute do lend themselves to settlement by mediation, as they are interest-based rather than positional (Berger, 2006); as noted previously a developer's interest is in maximizing the value of their land asset and local authorities are (or ought to be) interested solely in protecting the public interest. This means that there is wide scope for the parties to move from their opening gambits to reach a consensus, so long as the local authority is able to reconcile a compromise with the public interest.

In England and Wales there are three different ways that an appeal can be 'heard'; by written representations, by hearing or by public inquiry (Isaac et al, 2016). While there is no right, under English law, for third-parties to appeal an initial planning decision (Norton, 2017), once an appeal has been lodged by a developer, interested third parties, such as neighbouring local authorities, commercial rivals, neighbours, statutory bodies or local groups, are entitled to participate in the appeal process, should they so wish, by submitting written representations and giving oral testimony at any hearings or inquiries (Harwood, 2013). The entitlement of third parties to participate proactively in the appeal process is an added complication of English planning law (Brooke, 2015), and it follows that if the judicial appeal process is going to be replaced with a formalised first-instance mediation regime, then that regime will need to accommodate at least the same level of third-party participation as is accommodated by the judicial process.

This presents both a challenge and a potential opportunity for the pro-mediation agenda; the challenge is to ensure that the rights of third parties to be represented within the planning appeal process are not compromised by the introduction of a formal mediation regime; the potential opportunity is to devise an alternative dispute resolution process which actually enhances third party participation. Whether or not this challenge and opportunity can be overcome and realised, respectively, forms the subject-matter of the following section of this paper.

It has been argued in the academic literature that mediation may also be a viable alternative to judicial enforcement action, i.e. where local authorities bring proceedings against land owners who have failed to comply with the conditions and limitations of their planning permission (Pugh-Smith, 2011). This type of planning dispute does not usually involve third parties, even though enforcement proceedings are often instigated as a result of third party referrals. 
In the opinion of this present author, there are some immediate and obvious concerns with the utilization of mediation as a first-instance enforcement mechanism; notwithstanding the definitional uncertainty surrounding the word 'mediation' and the huge variety of different processes which are subsumed by the umbrella of this term, it is unlikely that the threat of enforcement action would have the same deterrent effect if mediation replaced litigation as the dispute resolution mechanism of first instance. In fact, the adoption of a formal mediation regime for the resolution of such disputes could lead developers to believe that the conditions and limitations attached to planning permission grants are somehow negotiable post facto. Unfortunately, there is no empirical data available to test this thesis or to quantify the potential reduction in compliance with planning conditions which might result from the adoption of a formal mediation regime for planning enforcement action. There is, however, in the context of the criminal justice system, evidence that mediation has less of a deterrent effect than more formal enforcement mechanisms (Roberts, 2002); it seems likely, to this author, that a similar effect would be observed within the context of the UK planning system.

Legal precedent is also valuable in this arena, and the adoption of a formalised mediation regime could curb the development of planning law (Costello, 1996). As noted previously, the substance of a planning dispute usually hinges around the correct interpretation of a particular law or policy; if such disputes are routinely mediated then future litigants may not be able to enjoy the precedential value of the outcome of that dispute (Arnavas, 2014). While the adoption of a formalised mediation regime might-and the evidence is by no means compelling —cause a reduction in litigation costs for disputing parties, it would almost certainly cause more disputes to arise in the first place, as mediation outcomes are usually bespoke, confidential, idiosyncratic, party-controlled and not legally binding on anyone except for the signatories to the mediated settlement agreement (Hopt and Steffek, 2013). This unintended consequence of the adoption of such a regime could, ultimately, be more costly than the problem which the regime seeks to overcome.

In addition, if the majority of planning disputes were settled through traditional mediation, which would presumably be the objective of a formalised mediation regime, then local and regional disparity in planning decisions would be exacerbated, because the settlement of those disputes would be controlled by the local authorities involved and not by an independent tribunal applying national laws, policies and principles. This would be at odds with the UK government's focus on addressing these kinds of disparity in the application of planning law (Thomson and Maginn, 2012).

\section{How might 'mediation' satisfy or exceed the minimum requirements for community participation?}

It has been argued in the academic literature that mediation can be an highly effective mechanism for the resolution for disputes which occur at public-private interface (Alexander, 2006). Various models have been proposed to combine conflict resolution and public participation through mediation and such schemes have been shown to be highly successful at empowering local communities and building trust between community interest groups, private parties and local government (Spencer and Brogan, 2006). 
However, these scheme are invariably complex, and their success depends upon the quality of the preparatory work undertaken by the mediator and his or her skill in managing what is tantamount to a multi-party (facilitated) negotiation (Sanoff, 2000). As Leibmann argues, in a multi-party mediation involving various interest groups it is important for the mediator to meet with each group individually to discern the main issues which they wish to be addressed or resolved during the mediation process (Liebmann, 1998); this is painstaking and meticulous work and would take considerable time to manage at a considerable cost. In larger disputes involving a substantial number of parties it may even be necessary to appoint more than one mediator in order to preserve the neutrality of the process and ensure that all the parties interests are adequately addressed (Cooley and Lubet, 2003).

It is no straightforward task to evaluate the likely cost of such a process and it is by no means clear that mediation lends itself naturally to community or third-party participation; in fact, as has been argued above, the management of the mediation process can be very complex when there are more than two parties involved (Cooley and Lubet, 2003). Various questions would need to be resolved in order to devise a formalised mediation regime capable of replacing the existing appeals process. For example, would third parties be allowed to participate actively in the mediation process, or would they simply be allowed to make representations in the hope that these representations would influence the negotiating positions of the parties? If the former was the case, then would the mediation fail if consensus could not be reached between all the parties to the mediation? This would be giving third parties far more control over the outcome of planning disputes than the current appeals system and would likely reduce considerably the success rate of the mediation regime, as a successful outcome would be contingent upon a consensus being reached between a larger number of parties. On the other hand, if the latter was the case, then there would be no guarantee that third-party representations would be taken into account by the disputants, at all, as in a traditional mediation the parties to the dispute retain control over the substance of the settlement agreement (Hardy and Rundle, 2010).

There does exist at least one case study of mediation being used successfully as a consultation mechanism for stakeholders involved in planning proposals for a brownfield site (Williams, 2010). However, this was not a planning dispute, per se, and therefore is of limited value as a procedural precedent for the management of multiparty mediations. As Craig Howell Williams QC concedes, the inclusion of multiple third parties in the mediation process may not only present practical problems but may represent a fundamental obstacle to the use of this form of ADR in the planning context (Williams, 2010).

\section{How might 'mediation' overcome the precedent issue identified supra?}

One potential solution here would be to vet all disputes, prior to mediation, to ensure that they are not likely to have important precedential value on a point of law. A similar evaluation process is used in Canada, where judicial mediation is routinely utilised to resolve both civil and criminal disputes (Alexander, 2006). However, this would add another layer of procedural complexity to the process and add further costs, which would need to be quantified before giving any serious consideration to its adoption. 
In addition, it has been argued that a significant number of planning disputes do involve points of law, and therefore this 'solution' might actually prevent a large number of planning disputes from being mediated, undermining raison d'etre for a formalised mediation regime within the UK planning system.

Another potential solution would be to choose a different alternative dispute resolution procedure entirely, such as arbitration, which is capable of producing awards with precedential value (Rovine, 2013), even though arbitral awards are not per se binding on third parties (Smeureanu, 2011). In the following section of this paper, this author will discuss a form of mediation which has been adopted in Italy, under which the mediator-a highly trained legal professional-is entitled to hand down an award of his or her own device, if the parties are unable to reach consensus. It is possible that awards produced by this mediation-arbitration hybrid process would be capable of having precedential value, so long as the mediator also ensured that the parties were not free to reach a private consensus on a valuable point of law. In other words, the evaluation process described in the previous paragraph of this section would be undertaken by the mediator, who would arbitrate points of law while allowing other aspects of the dispute to be mediated, if possible (Telford, 2000).

In any event, the discussion of such a proposal falls outside the strict scope of this present research study, and it is not clear whether or not the adoption of such a scheme would ameliorate concerns about the exacerbation of regional disparities in decision-making by local planning authorities.

In conclusion to this section, while a substantial number of planning disputes are likely of a kind which lend themselves naturally to resolution by mediation, it is not at all clear how the present rights of third parties which are enshrined within the existing English planning system-namely, to be represented in the planning appeals process-would be replicated or enhanced by the use of mediation. In addition, legitimate concerns have been raised by this author that the use of mediation in this context could exacerbate the regional disparity in public decision-making which the UK government seems so keen to address. Further, an increase in the number of planning disputes being resolved through mediation could stifle the development of English planning law, by restricting the flow of judicial precedent. While it might be possible to overcome this challenge by introducing a pre-mediation dispute evaluation or screening procedure, to decide which disputes ought to be resolved by a judge and which ought to be mediated, ultimately this would add to the infrastructure costs of the UK planning system and would probably mean only a small number of disputes end up being mediated (as planning disputes often involve disagreements on the appropriate application of law and policy).

Finally, it is not at all clear that mediation would be a viable alternative to judicial enforcement in this context, as the adoption of a formalised mediation regime for these kinds of 'dispute' could undermine the deterrent effect of the conditions annexed to planning permission grants. Further research would be required in order to test this thesis, but empirical data pertaining to the effect of introducing mandatory mediation into other parts of the UK legal system indicates that this may well be the case. 

authorities?

In this section, this author critically evaluates the appropriateness of mediation as a formal alternative to the existing judicial appeal and judicial review processes, bearing in mind the public interest in the outcome of planning disputes.

It has been argued in the academic literature that mediation is not always an appropriate tool for the resolution of planning disputes between local authorities and developers, because its success, as a process, depends upon both parties reaching a compromise solution and the public interest ought to be non-negotiable (Brooke, 2015). In other words, local authorities are constitutionally bound to determine and protect the public interest (Harlow et al, 2003) and it is not appropriate for local authorities to compromise on that position in order to accommodate the private interests of property developers.

It is important, here, to compare the process of mediation with the process of formal litigation and ask the question, what makes mediation less appropriate than formal litigation as a guardian of the public interest? The most obvious answer is that a judge is competent and duty-bound to protect the public interest whereas a mediator or the parties to a mediation are not. The role of the courts is not to resolve disputes but to give meaning and operational content to the values of society, together 'the public interest'. In contrast the role of a mediator is to facilitate the settlement of a specific dispute between two or more parties. Concerns have been raised in the academic literature as to whether the public interest can be appropriately safeguarded if publicprivate disputes are diverted towards non-legal channels, such as mediation, which are not subject to the same procedural safeguards as formal litigation (Roberts, 2013).

While this argument enjoys intuitive appeal, it is predicated upon the assumption that planning authorities always make the right decisions, ab initio, which of course is not the case. A planning decision will be informed by an authority's own interpretation of applicable local, regional and national laws and policies and when private parties believe that these laws and policies have been misinterpreted or misapplied then a dispute may arise. For such disputes, the mediation process could actually help the parties to better understand the arguments of their counter-parts and result in a compromise solution which better serves the public interest than the respective initial positions of the disputing parties. There is a strong public interest in reversing inappropriate decisions of public authorities as quickly as possible; as argued previously, delayed dispute resolution slows down the rate of investment into the UK's property sector and increases the administrative and legal costs of the parties involved and the Exchequer. Consequently, mediation could, in theory, serve an important function in protecting the public purse, by providing an informal and (arguably) inexpensive preliminary appeal or review process.

Even when a local authority's initial planning decision did represent the public interest at the moment in time when that decision was reached, the public interest is not a static animal; the process of mediation might bring new information and options to light which could justify a re-evaluation of the local authority's initial position. 
For example, a local authority might decide to reject a planning application on 'green belt' land to preserve and protect its open spaces and to control urban sprawl. While it would certainly be inappropriate for that local authority to compromise on its position, solely to accommodate the private interests of a developer, a compromise solution may involve that developer offering to provide additional investment into social housing, for example, which could outweigh the authority's initial objections to that development. While, historically, this kind of public-private negotiation was viewed as a form of bribery, since the enactment of section 106 of the Town and Country Planning Act 1990, it is now commonplace for developers to offer local authorities financial incentives to approve applications which might otherwise be deemed contrary to the public interest and there is now a statutory framework governing the procedure for this kind of negotiation.

In light of the existence of section 106, which specifically encourages negotiation between developers and local authorities, it is difficult to find a principled objection to the idea of a mediation-led settlement process, even where that settlement results in the reversal of an otherwise appropriate and lawful planning decision; the settlement agreement may better serve the public interest than the initial decision, as it may result in a greater public benefit than the benefit which would have resulted had the initial position or decision of a local authority been upheld. However, in reality, it is difficult to see what role mediation could play in this scenario when there already exists a statutory framework governing section 106 negotiations and those negotiations are so similar to the mediation process, albeit without an independent third party sitting between the disputants. This is a point that was raised by Pauline Roberts of Nathanial Litchfield and Partners during the semi-structured interview conducted as part of this research study. When asked whether mediation might be a useful next-step, if a section 106 negotiation does get stuck, as opposed to proceeding directly with a formal appeal, Mrs Roberts replied in the negative: "If section 106 negotiations do become stuck, then the correct approach is to lodge an appeal within the strict time limits or you will risk not getting a decision at all. The negotiations are usually led by experienced consultants-and are usually successful-and so, if section 106 negotiations become stuck there is a strong chance that mediation would also fail to produce a compromise solution. For that reason, it is preferable to lodge a formal appeal on grounds of non-determination."

Based upon these expert insights, it seems clear that if mediation is going to play an effective role in expediting section 106 negotiations, the mediation process would need to be of a type capable of replacing the function of the appeal process, rather than the function of the section 106 negotiation process. After all, if the mediation process simply usurped the function of the section 106 negotiation, then it would be largely redundant; it is not in the interests of either developers or local authorities to protract their negotiations and it is difficult to see how the presence of a third party mediator could, by itself, render mediation more effective than negotiation, especially when the parties to these kinds of disputes are experts in their field.

Additionally, guarantees would also need to be offered to ensure that participation in the mediation process did not prejudice the applicants' right to appeal on grounds of non-determination, should the mediation fail, a concern which is clearly implicit in Mrs Robert response, supra. 
This thesis seems to be supported by Martin Burns, the head of the RICS Dispute Resolution Services team, who argues that mediation could play a useful role in ensuring that local authorities engage in a timely manner with the section 106 process, for example by making mediation compulsory where a section 106 negotiation has failed to produce a definitive outcome:

$A D R$ can be an effective mechanism to help speed up the planning process and, in particular, S106 negotiations. But perhaps it should be that, only in circumstances where S106 negotiations do not result in S106 agreements, and developers and local authorities manifestly fail to comply with new statutory timescales, should the prospect of decisions being taken out of the control of local authorities actually become reality (Burns, 2016).

While Martin Burns does not overtly advocate the adoption of a special form of mediation here, he does indicate that once the negotiations have proceeded to mediation, the ultimate decision would be 'taken out of the control of local authorities'. As discussed in section 1 of this paper, mediation does not usually involve decisions being taken out of the hands of the parties, as the mediator's role is facilitative as opposed to being determinative. The only way to make sense of Burn's comments is to assume that he is referring to a mediation process which can result in a mediator reaching a binding decision, in the event that the parties are unable to negotiate a mutually agreeable compromise solution. In other words, it seems that Martin Burns is advocating for the adoption of some form of mediation-arbitration hybrid to sit between the section 106 negotiation and formal appeal processes.

When asked to comment upon the viability of such a process, during the semistructured interview, Mrs Pauline Roberts replied:

\begin{abstract}
If a local authority failed to reach a section 106 decision in a timely manner, and there existed a compulsory and binding form of mediation where the mediator could assume the role of an arbitrator if the mediation failed to produce a satisfactory section 106 agreement, then this could indeed be more attractive to a developer than a formal appeal. However, its value would probably be limited to larger schemes only, as section 106 negotiations on small or simple schemes tend not to get stuck [2].
\end{abstract}

This response suggests that there may indeed be some merit in introducing an alternative dispute resolution mechanism between section 106 negotiations and the existing appeals process; however, it is clear that traditional mediation is not the right tool for the job and that a hybrid of mediation and arbitration may be more appropriate.

It is worth a quick mention that a mediation-arbitration or 'med-arb' regime has recently been introduced in Italy. Under this regime, if the parties are unable to reach an agreement, or if one of the parties does not attend the mediation, then the mediator is entitled to propose legal solutions and the parties to the mediation are bound to accept the mediator's final proposals. Up until the final decision has been handed down, the parties remain free to negotiate not only with their counter-parts but also with the mediator, so they do retain a high degree of control over the process and also the outcome. 
This scheme has been criticised heaving within the academic literature for a number of reasons. First, it has been argued that this process is at odds with the very definition of mediation and compromises the neutrality of the mediator. While this present author agrees that this form of mediation is atypical, as was argued at length in section 1 of this paper, there is no such thing as a standardised mediation process and consequently it is difficult to see why this argument be should be given much weight.

Second, it has been argued that this kind of process would require a degree of skill and experience beyond that which can be expected from a normal mediator. As Hanks argues, "In any case, it indicates a particular need to ensure that mediators are adequately trained and have the requisite knowledge to propose solutions that are legally enforceable and in the parties' interests. Thus, the changes implemented by Italy will only be effective if they are complemented by the education of legal professionals and the training of a large number of mediators to handle the inevitable increase in claims (Hanks, 2012)."

In the opinion of this present author, mediators should be adequately trained with the requisite knowledge of the subject-matter of the disputes they preside over irrespective of the kind of mediation which they are undertaking. This is supported by the empirical evidence cited in section 1 of this paper, which proves that there is a positive correlation between the skill of a mediator and the prospect for successful resolution of a dispute. In the context of planning disputes, which are in any event highly specialised, it is particularly important that the mediator is sufficiently knowledgeable in the intricacies of planning law. Consequently, it is difficult to see how this is a legitimate objection to the adoption of this kind of med-arb mediation.

Hanks' concluding remark that the success of Italy's new regime will depend upon the training of a large number of mediators to handle the inevitable increase in claims is somewhat misplaced; this seems to be an objection to the mandatory nature of the process and not to the role of the mediator per se. If a mandatory mediation regime is going to be introduced, it follows that the relevant authorities will need to ensure that there is adequate infrastructure in place to accommodate the increased case load; however, if the regime failed because of a lack of infrastructure it would not be appropriate to conclude that the regime failed because of the role of the mediator or the nature of the mediation process being employed.

Further research would be required in order to test the viability of introducing such a scheme in England and Wales. It will be very interesting to see how the Italian regime works in practice although, for the reasons articulated in section 1, one has to be careful not to assume that a system which works well (or badly) in one jurisdiction would perform equally well in another.

In conclusion, this present author rejects the public interest objections to the introduction of a formalised mediation regime for the resolution of disputes flowing from failed section 106 negotiations. However, this author is not convinced that mediation could serve a useful function here; it is very similar in nature to negotiation and it is difficult to see why mediation would succeed where negotiation has failed, especially in this context where the disputing parties are highly professional, impersonal and are interest-oriented as opposed to being positional. 
931 In any event, it seems that section 106 negotiations are usually successful so there is 932 no real problem here for mediation to solve. If a formalised mediation regime is going 933 to be adopted to sit between section 106 negotiations and the appeals process, it 934 ought to replace the functions of the latter and not the former. In the opinion of this 935 present author, for the reasons set out in this section, mediation, in its traditional nondeterminative form, is the wrong tool for the job. 
What lessons may be learned from the respective mediation regimes for

\section{planning disputes in Scotland and Australia and how might these regimes inform planning law and policy in England and Wales?}

In this short section, this author examines the different 'mediation' regimes which have been introduced into the planning systems of New South Wales and Scotland. The experiences of New South Wales reinforce the idea that mediation in its traditional form is not likely to be a viable alternative to court litigation for the resolution of planning disputes. The experiences of Scotland throw light on the potential role for mediation at the pre-planning stages and the need for further research here.

\section{New South Wales}

ADR has enjoyed a lengthy but turbulent history within New South Wales' planning system. A dedicated Land and Environment Court ['LEC'] was established in 1979 to try and move away from the adversarial style of dispute resolution which characterises the judicial process in the vast majority of common law jurisdictions. The emphasis of the LEC was on speed and informality. Disputes were presided over by Judges and/or non-lawyers ('Assessors') —experts in the field of planning, for example surveyors, town planners, architects and engineers (Ratcliffe et al, 2009)-depending upon whether the dispute involved complex points of law or technical planning issues. In tandem with this judicial process, the 1979 Act emphasised the importance of ADR and introduced a Conciliation Conference mechanism to allow parties to meet with an Assessor to resolve their planning disputes in a non-adjudicative manner; however, this mechanism was so unsuccessful in resolving disputes that it was ultimately disbanded in the 1990s and replaced with court-annexed mediation (Ryan, 2002). This was also largely unsuccessful; in its early years only $4 \%$ of all planning disputes were referred to this mediation mechanism, and only $60 \%$ of those disputes were resolved successful (Dearing, 2011). One of the reasons for the low number of referrals to this mediation process was that it remained voluntary and local authorities demonstrated a preference for their disputes to be resolved by the Land and Environment Court, as it was felt that this two-tier Court was better equipped to deal with complex legal issues than Assessor- or, as they latterly became known, Commissioner-facilitated mediation (Wulf, 2007).

In 2010, the Land and Court Act 1979 (NSW) was reformed and a mandatory conciliation-arbitration system was introduced for the resolution of certain classes of residential planning appeals. This process has been largely successful-resulting in a substantial increase in the number of planning appeals being resolved without recourse to formal litigation-and has even been used in a limited number of cases as an alternative to judicial review proceedings. This supports the argument made in sections 2 and 3 of this paper, that if an alternative dispute resolution mechanism is going to be introduced as an alternative to court litigation, then a hybrid between mediation and arbitration is preferable to traditional mediation. 


\section{Scotland}

A Scotland-wide review of the strategic planning framework undertaken in 2002, along with a public consultation on public involvement in planning, revealed high levels of dissatisfaction and alienation between the electorate and the Scottish planning authorities (Hague and Jenkins, 2005).

One of the reform proposals to emerge from this process was the introduction of a third party right of appeal of first-instance planning decisions (Scottish Government, 2004). Developers responded that the introduction of such a right, which is already enjoyed in various forms in various jurisdictions including Sweden, Ireland and New South Wales, would increase substantially the number of appeal applications and hamper the efficiency of the planning process (Sidaway, 2013). On the other hand, some authors and commentators have argued that the introduction of such a right would force developers to invite stakeholders to participate in the planning process at an earlier stage, which would improve public confidence in the planning system and mitigate the potential surge in third party planning appeals (Sidaway, 2013). Arguably, it is here, at the pre-planning stages, that mediation might have a valuable role to play. It will be recalled from the analysis undertaken in section 2 of this paper that there does exist empirical evidence in support of this idea; while this kind of mediated preplanning consultation process may be costly and time-consuming, if there existed a third party right of appeal, then developers would be incentivised to fund this exercise, to reduce the likelihood of a third party appeal being lodged (Jackson, 2010). Perhaps the most convincing argument for moving the public consultation process to the preplanning stage is that it gives developers and architects the opportunity to devise a scheme which has the highest prospects of success; if the developer waits until the appeal stage of the process to contest stakeholder objections then the scope for amending the proposals and the costs of doing so will be greatly increased. This is a view confirmed by Pauline Roberts of Nathaniel Litchfield and Partners, although she confirms that her clients usually invite interested third-parties to participate in the preplanning process in any event, to de-risk the prospects of an application being refused on the basis of third party objections.

While, ultimately, this reform was not implemented in the Scottish Planning Act (MaCafferty et al, 2009), nevertheless this author believes that there is scope for further research here. While an evaluation of the role of mediation at the pre-planning stage falls outside the scope of this present paper-as this paper is concerned with mediation as a dispute resolution mechanism and not as a dispute prevention strategy-nevertheless, based upon the otherwise gloomy picture painted by this research for the role of traditional mediation in planning, of all the reform proposals discussed within this paper, the introduction of pre-planning mediation (either as a requirement or as an indirect effect of introducing enhanced third party rights at a later stage in the planning process) seems to hold the most promise, if not in terms of costeffectiveness, certainly in terms of enhanced public participation. 


\section{Final conclusions and recommendations for further research in this field.}

The primary objective of this present study was to evaluate the viability of mediation as a mechanism for the resolution of planning disputes which occur between developers and public authorities, bearing in mind the overwhelming support amongst practitioners and commentators for the adoption of a more formalised mediation regime in the UK planning system.

Surprisingly, the findings of this research indicate that, presently, there is no strong case for the introduction of such a regime, at least not as an alternative to court litigation. Firstly, the term 'mediation' is so poorly defined by its proponents that it is not entirely clear what kind of dispute resolution mechanism any of these authors are, in fact, proposing. Second, there does not exist an adequate evidence-base from which to justify the implementation of a formalised mediation regime within the UK's planning system, on grounds of cost-effectiveness. Thirdly, while a substantial number of planning disputes are likely of a kind which lend themselves naturally to resolution by mediation, it is not at all clear how the present rights of third parties which are enshrined within the existing English planning system-namely, to be represented in the planning appeals process-would be replicated or enhanced by the use of mediation. Fourthly, the adoption of a formal mediation regime of the kind proposed could exacerbate the regional disparity in public decision-making which the UK government seems so keen to address and could stifle the development of English planning law, by restricting the flow of judicial precedent. Fifthly, it is not at all clear that mediation would be a viable alternative to judicial enforcement, as the adoption of a formalised mediation regime for these kinds of 'dispute' could undermine the deterrent effect of the conditions annexed to planning permission grants. Sixthly, there does not seem to be a strong case for introducing a mediation process to sit between failed section 106 negotiations and the judicial appeals process; if a section 106 negotiation fails then a mediation would likely fail for the same reasons.

Further research is required to test the viability of (i) introducing a mediation-arbitration or conciliation-arbitration procedure as an alternative to court litigation for the resolution of planning disputes; and, (ii) introducing a pre-planning mediation procedure to improve the efficiency of the planning process and improve stakeholder participation. 
1080

1081

1082

1083

1084

1085

1086

1087

1088

1089

1090

1091

1092

1093

1094

1095

1096

1097

1098

1099

1100

1101

1102

1103

1104

1105

1106

1107

1108

1109

1110

References:

\section{Cases:}

Australians for Sustainable Development Inc v Minister for Planning [2011] NSWLEC 33.

Catherine Hill Bay Progress Association v Minister for Planning \& Another [2011] NSWLEC 40698.

Legislation:

Land and Environment Court Act 1979 (NSW)

Planning Act 2008 (UK)

Planning and Compulsory Purchase Act 2004 (UK)

\section{End Notes}

[1] It is very difficult to derive a definition which distinguishes conciliation and mediation as, in practice, these processes are both forms of facilitated negotiation, albeit with different procedural rules. See E. Uwazie (2014) Alternative Dispute Resolution and Peace-building in Africa. Cambridge Scholars Publishing. 170; and, M. J. Broyde (2017), Sharia Tribunals, Rabbinical Courts, and Christian Panels: Religious Arbitration in America and the West. Oxford University Press. 87.

[2] Excerpt from the transcript of the semi-structured interview undertaken, by this author, with Mrs P. Roberts of Nathaniel Litchfield and Partners.

\section{Books and journals:}

Agapiou, A., and D. Ilter (2016) Court-Connected Construction Mediation Practice: A Comparative International Review. Taylor \& Francis.

Alexander, N., M (2006) Global Trends in Mediation. Kluwer Law International.

Arnavas, D., P (2004) Alternative Dispute Resolution for Government Contracts. CCH Incorporated.

Barker, K (2006) Barker Review of Land Use Planning: final report recommendations. HM Treasury.

Bacow, LS \& M Wheeler (2013) Environmental dispute resolution. Springer Science \& Business Media, London, p. 118.

Barlow, J., and S. Duncan (1994) Success and failure in housing provision: European systems compared: Policy, planning, and critical theory. Pergamon Press. 
Barsky, A., E (2014) Conflict Resolution for the Helping Professions .Oxford University Press.

Bercovitch, J., and R. D. W. Jackson (2009) Conflict Resolution in the Twenty-first Century: Principles, Methods, and Approaches. University of Michigan Press.

Berger, K., P (2006) Private Dispute Settlement: Negotiation, Mediation, Arbitration: Handbook. Kluwer Law International.

Blake, S., J. Browne and S. Sime (2016) A Practical Approach to Alternative Dispute Resolution. Oxford University Press.

Bondy, V., and L. Mulcahy (2009) 'Mediation and Judicial Review: An empirical research study'. Public Law Project. [Online] $<$ http://www.nuffieldfoundation.org/sites/default/files/files/MediationandJudicialRevie w.pdf> accessed 9 August 2017.

Brooke, $\mathrm{H}$ (2015) 'The Role of Mediation in Planning and Environmental Disputes'. 16 December. [Online] <https://sirhenrybrooke.me/2015/12/16/the-role-of-mediation-inplanning-and-environmental-disputes/> accessed 17 July 2017.

Brooker, P., and S. Wilkinson (2010) Mediation in the Construction Industry: An International Review. Routledge.

Brooker, P (2013) Mediation Law: Journey Through Institutionalism to Juridification. Routledge.

Broyde, M., J (2017) Sharia Tribunals, Rabbinical Courts, and Christian Panels: Religious Arbitration in America and the West. Oxford University Press.

Burns, M (2016) 'Best Laid Plans'. 24 June. New Law Journal, Issue 7704 [Online] <https://www.newlawjournal.co.uk/content/best-laid-plans-1> accessed 19 July 2017.

Burrell, N., A., M. Allen, B. M. Gayle and R. W. Preiss (2014) Managing Interpersonal Conflict: Advances Through Meta-Analysis. Routledge.

Chern, C (2014) The Commercial Mediator's Handbook. CRC Press.

Clark, B (2012) Lawyers and Mediation. Springer Science \& Business Media.

Clark, D., S (2007) Encyclopedia of Law and Society: American and Global Perspectives. SAGE.

Cooley, J., W., and S. Lubet (2003) Arbitration Advocacy. National Institution for Trial Advocacy.

Cortez, P (2016) The New Regulatory Framework for Consumer Dispute Resolution. Oxford University Press.

Costello, E., J (1996) Controlling conflict: alternative dispute resolution for business. $\mathrm{CCH}$ Inc. 
Craig Howell Williams QC (2010) 'Planning Ahead'. 23 November. [Online] $<$ https://www.ftbchambers.co.uk/sites/default/files/planning-ahead.pdf> accessed 1 August 2017.

Crichton, M., Dr. P. O'Connor, Prof. R. Flin (2013) Safety at the Sharp End: A Guide to Non-Technical Skills. Ashgate Publishing.

Crook, T., J. Henneberry and C. Whitehead (2016) Planning Gain: Providing Infrastructure and Affordable Housing. John Wiley \& Sons.

Cullingworth, B., V. Nadin, T. Hart, S. Davoudi, J. Pendlebury, G. Vigar, D. Webb and T. Townshend (2014) Town and Country Planning in the UK. Routledge.

Dearing, D., 'Dispute Resolution in Australia' (2011) [Online] $<$ http://www.civiljustice.info/cgi/viewcontent.cgi?article=1003\&context=adrcourt> Accessed 2 August 2017.

Department for Communities and Local Government (2006) Planning Obligations: Practice Guidance. DCLG, London, ch. 7.

Goldberg, S.B (2003) Dispute resolution: Negotiation, mediation, and other processes. Aspen Law \& Business, New York, 50-54.

Hague, C., and P. Jenkins (2005) Place Identity, Participation and Planning. Psychology Press.

Hanks, M., 'Perspectives on Mandatory Mediation' (2012) 950 [Online] < http://unswlawjournal.unsw.edu.au/sites/all/themes/unsw/images/MelissaHanks.pdf> accessed 1 August 2017.

Hardy, S., and O. Rundle (2010) Mediation for Lawyers. CCH Australia Limited.

Harlow, C., P. P. Craig and R. Rawlings (2003) Law and Administration in Europe: Essays in Honour of Carol Harlow. Oxford University Press.

Harwood, R (2013) Planning Enforcement. A\&C Black.

HM Government (2007) Planning for a Sustainable Future: White Paper Cm 7120. Stationery Office, London, paras. 9.60, 9.61.

Hopt, K., J., and F. Steffek (2013) Mediation: Principles and Regulation in Comparative Perspective. Oxford University Press.

IAC-MEBM (2016) International Academic Conference on Management, Economics, Business and Marketing in Vienna. Austria (IAC-MEBM 2016).

IRS (1971) Internal Revenue Bulletin. U.S. Government Printing Office.

Isaac, D., J. O'Leary and M. Daley (2016) Property Development. Blackwell.

Jackson, R., M (2010) Review of Civil Litigation Costs. The Stationery Office. 
Janssen-Jansen, L., M. Spaans and M. van der Veen (2008) New Instruments in Spatial Planning: An International Perspective on Non-financial Compensation. IOS Press.

Kaufman, S, CP Ozawa \& DF Samuel (2014) 'Evaluating participatory decision processes: Which methods inform reflective practice?' 42, Evaluation and program planning 11, pp. 14-15.

Levy, J., M h (2016) Contemporary Urban Planning. Taylor \& Francis.

Liebmann, M (1998) Community and Neighbourhood Mediation. Cavendish Publishing.

MacLaran, A., V. Clayton and P. Brudell (2007) Empowering communities in disadvantaged urban areas: towards greater community participation in Irish urban planning. Combat Poverty Agency.

MacNaughton, A., L., and J. G. Martin (2002) Environmental Dispute Resolution: An Anthology of Practical Solutions. American Bar Association.

McCafferty, P., D. Miller and N. Davidson (2009) Neoliberal Scotland: Class and Society in a Stateless Nation, Patricia McCafferty. Cambridge Scholars Publishing, 2009.

Morasso, S., G (2011) Argumentation in Dispute Mediation: A Reasonable Way to Handle Conflict. John Benjamins Publishing.

National Association of Legal Assistants (2014) NALA Manual for Paralegals and Legal Assistants: A General Skills \& Litigation Guide for Today's Professionals. 6th ed., Cengage Learning.

Nicholson, D (2009) Environmental Dispute Resolution in Indonesia. BRILL.

Norton, P (2017) Public Consultation and Community Involvement in Planning: A Twenty-First Century Guide. Taylor \& Francis.

One Scotland (2009) 'A Guide to the Use of Mediation in the Planning System in Scotland'. March. [Online] <https://beta.gov.scot/publications/guide-use-mediationplanning-system-scotland/documents/0078790.pdf> accessed 18 July 2017.

Pemberton, S., D. Peel and G. Lloyd (2015) 'The 'filling in' of community-based planning in the devolved UK?' 181 Geographical Journal 1.

Planning Inspectorate (2010) Mediation in Planning. National Planning Forum.

Poon, G., P (2010) The Corporate Counsel's Guide to Mediation. American Bar Association.

Pretty, D., and J. Killian (2008) Killian Pretty Review: Planning Applications: A faster more responsive system. CLG November. 
Pugh-Smith, J. (2011) 'Securing Common Ground'. 39 Essex Street Chambers. May. [Online] <http://www.civilmediation.org/downloads-get?id=376> accessed 30 July 2017.

Ratcliffe, J., M. Stubbs and M. Keeping (2009) Urban Planning and Real Estate Development. Routledge.

Roberts, A., R (2002) Handbook of Domestic Violence Intervention Strategies: Policies, Programs, and Legal Remedies. Oxford University Press.

Roberts, M (2013) A-Z of Mediation. Palgrave Macmillan.

Roberts, M (2014) Mediation in Family Disputes: Principles of Practice. Ashgate Publishing.

Rovine, A., W (2013) Contemporary Issues in International Arbitration and Mediation: The Fordham Papers. Martinus Nijhoff Publishers.

Ryan, P (2002) 'Court of Hope and False Expectations: Land and Environment Court 21 Years On'. 14 Journal of Environmental Law 3.

Sanoff, H (2000) Community Participation Methods in Design and Planning. John Wiley \& Sons.

Schrumpf, F., D. K. Crawford and R. J. Bodine (1997) Peer Mediation: Conflict Resolution in Schools. Research Press.

Scottish Government, 'Rights of Appeal in Planning' (April 2004) [Online] <http://www.gov.scot/Publications/2004/04/19206/35617> accessed 4 August 2017.

Shepley, C (1997) 'Mediation in the planning system'. Town and Regional Planning 42.

Shepley, C (2006) Mediation in Planning - a Thinkpiece. National Planning Forum.

Shepley, C (1996) Mediation in Planning. RTPI National Conference.

Sidaway, R (2013) Resolving Environmental Disputes: From Conflict to Consensus. Routledge, 263.

Smeureanu, I., M (2011) Confidentiality in International Commercial Arbitration. Kluwer Law International.

Spencer, D., and M. Brogan (2007) Mediation Law and Practice. Cambridge University Press.

Storskrubb, E (2008) Civil Procedure and EU Law: A Policy Area Uncovered. Oxford University Press.

Stubbs, M., D (1997)'The new panacea? An evaluation of mediation as an effective method of dispute resolution in planning appeals'. 2 International Planning Studies 3. 
Susskind, L., M. van der Wansem and A. Ciccarelli (2000)Mediating land use disputes: pros and cons. Lincoln Institute of Land Policy.

1261 Telford, M., E (2000) Med-arb: a viable dispute resolution alternative. IRC Press.

1262 Thompson, S., and P. Maginn (2012) Planning Australia: An Overview of Urban and 1263 Regional Planning. Cambridge University Press.

1264 Uwazie, E (2014) Alternative Dispute Resolution and Peace-building in Africa. 1265 Cambridge Scholars Publishing.

1266 Watson, LM (2016) 'Planning, Organizing, Formatting and Executing the Mediation 1267 of a Complex, Multi-Party, Multi-Issue, Lawsuit', 9 Am. J. Mediation 111, p. 115.

Welbank, M., N. Davies and I. Haywood (2000) Mediation in Planning. Department of the Environment, Transport and the Regions.

1271 Welbank, M., N., N. Davies, I. Haywood, M. Shenfield, T. Ayvazyam, M. Grant and J. 1272 Dean (2002) Further Research into Mediation in the Planning System. Office of the 1273 Deputy Prime Minister.

1274 Wulf, $\mathrm{P}(2007)$ 'Court-ordered mediation in the Planning and Environment Court: Does 1275 it assist self-represented litigants?'18 Australian Dispute Resolution Journal, 149-161. 